\title{
Bismuth Layer Structured Ferroelectric Ceramics with High Mechanical Quality Factor
}

\author{
Hajime Nagata Member (Tokyo University of Science, nagata@takenaka.ee.noda.tus.ac.jp) \\ Yuji Hiruma Non-member (Tokyo University of Science, hirumay@takenaka.ee.noda.tus.ac.jp) \\ Muneyasu Suzuki Non-member (Tokyo University of Science, suzuki@takenaka.ee.noda.tus.ac.jp) \\ Tadashi Takenaka Member (Tokyo University of Science, tadashi@takenaka.ee.noda.tus.ac.jp)
}

Keywords : bismuth layer-structured ferroelectrics, mechanical quality factor; Curie temperature, ceramic resonator, domain wall motion

Piezoelectric ceramics have been widely used for several applications, such as those in filters for mobile communications, resonators for microprocessors, actuators for inkjet printers, etc. The materials used for these applications are currently based on lead titanate $\left(\mathrm{PbTiO}_{3}\right)$ and lead zirconate titanate (PZT), which are utilized with several compositional modifications.

The family of bismuth layer-structured ferroelectrics (BLSF) is one of attractive lead-free materials from the viewpoint of their application to electronic functional devices such as resonators and high temperature sensors etc. In the case of resonator applications, piezoelectric elements are used as inductors, so it is necessary that they have a large electrical quality factor, $Q_{\mathrm{emax}}$, in the inductance frequency region and mechanical quality factor, $Q_{\mathrm{m}}$, rather than a large electromechanical coupling factors, $k$. BLSFs are characterized by their high quality factors, $Q_{\mathrm{m}}$, and $Q_{\mathrm{emax}}$, and low temperature coefficient of resonance frequency, $T C F$. In addition, because of their small coupling factor, they could have higher resonance stability. Therefore, we have studied BLSF materials as an excellent candidate of lead-free materials for a ceramic resonator application. Especially, piezoelectric properties have been focused, aiming to obtain high $Q_{\mathrm{m}}$ values in BLSF ceramics. Many BLSF compositions with various Curie temperature, $T_{\mathrm{c}}$, were selected in this study, and these compositions are summarized in Table 1.

Ceramic samples were prepared by a conventional ceramic fabrication technique. Reagent-grade oxide, hydro-oxide or carbonate powders with $99.9+\%$ purity were weighed to obtain the stoichiometric compositions. These materials were mixed by ball milling and calcined at $800-850^{\circ} \mathrm{C}$ for $2 \mathrm{~h}$. After calcining, the ground and ball-milled powders were pressed into disks of $20 \mathrm{~mm}$ diameter and about $10 \mathrm{~mm}$ thickness. These disks were sintered at

Table 1. The list of bismuth layer-structured ferroelectrics and their abbreviations and Curie temperatures, $T \mathrm{c}$. The chemical formula of $\mathrm{BLSF}$ is generally represented by $\left(\mathrm{Bi}_{2} \mathrm{O}_{2}\right)^{2+}\left(\mathrm{A}_{m-1} \mathrm{~B}_{m} \mathrm{O}_{3 m+1}\right)^{2-}$, where $m$ is an integer corresponding to the number of BO6 octahedra in pseudo perovskite blocks

\begin{tabular}{|c|c|c|c|}
\hline Composition & $\# m$ & abbreviation & $T_{\mathrm{c}}\left({ }^{\circ} \mathrm{C}\right)$ \\
\hline $\mathrm{CaBi}_{2} \mathrm{Ta}_{2} \mathrm{O}_{9}$ & 2 & CBT & 933 \\
\hline $0.9 \mathrm{Bi}_{3} \mathrm{TiNbO}_{9}-0.1 \mathrm{Na}_{0.5} \mathrm{Bi}_{2.5} \mathrm{Nb}_{2} \mathrm{O}_{9}$ & 2 & NBTN-10 & 895 \\
\hline $\mathrm{Bi}_{3-x} \mathrm{Nd}_{x} \mathrm{TiTaO}_{9}(0 \leqq x \leqq 1)$ & 2 & BNTT- $x$ & $400-900$ \\
\hline $\mathrm{Sr}_{x-1} \mathrm{Bi}_{4-x} \mathrm{Ti}_{2-x} \mathrm{Ta}_{x} \mathrm{O}_{9}(1 \leqq x \leqq 2)$ & 2 & SBTT2 $(x)$ & $280-850$ \\
\hline $\mathrm{Bi}_{3-x} \mathrm{La}_{x} \mathrm{TiTaO}_{9}(0 \leqq x \leqq 1)$ & 2 & BLTT-x & $200-900$ \\
\hline $\mathrm{SrBi}_{2} \mathrm{Nb}_{1.9} \mathrm{~V}_{0.1} \mathrm{O}_{9}$ & 2 & SBNV & 439 \\
\hline$\left(\mathrm{Sr}_{1-\mathrm{x}} \mathrm{Ca}_{x}\right)_{2} \mathrm{Bi}_{4} \mathrm{Ti}_{5} \mathrm{O}_{18}(0 \leqq x \leqq 0.5)$ & 5 & SCBT- $x$ & $290-470$ \\
\hline
\end{tabular}

$900 \sim 1280{ }^{\circ} \mathrm{C}$ for $2 \mathrm{~h}$ in air. The crystal structures were confirmed by $\mathrm{X}$-ray diffraction analysis using $\mathrm{CuK} \alpha$ radiation through a $\mathrm{Ni}$ filter at a scanning speed of $1 \mathrm{deg} / \mathrm{min}$. Electrodes of fired-on $\mathrm{Ag}$ paste were formed for electrical measurements, such as dielectric and piezoelectric properties. Specimens for piezoelectric measurements were poled in stirred silicone oil. Applied field, $E_{\mathrm{p}}$, temperature, $T_{\mathrm{p}}$, and time, $t_{\mathrm{p}}$, in the poling process were about $7-12 \mathrm{kV} / \mathrm{mm}, 100-300^{\circ} \mathrm{C}$ and $5-15 \mathrm{~min}$, respectively. Piezoelectric properties were measured by means of a resonance-antiresonance method on the basis of IEEE standards, using an impedance analyzer (YHP 4192A and 4194A). A longitudinal vibration of the (33) mode was measured using a rectangular specimen of $2 \times 2 \times$ $4 \mathrm{~mm}^{3}$.

The $Q_{\mathrm{m}}$ values of (33) mode were plotted as a function of their Curie temperature, $T_{\mathrm{c}}$., shown in Fig. 1 . The $Q_{\mathrm{m}}$ increased with increasing the $T_{\mathrm{c}}$ in the low $T_{\mathrm{c}}$ compositions below $500^{\circ} \mathrm{C}$. It is considered to relate with the domain wall pinning because the coercive field, $E_{\mathrm{c}}$ also increased with increasing the $T_{\mathrm{c}}$. However, in the high $T_{\mathrm{c}}$ compositions above $750^{\circ} \mathrm{C}$, the $Q_{\mathrm{m}}$ decreased with increasing the $T_{\mathrm{c}}$ contrary, because of the difficulties in poling treatment due to the high $E_{\mathrm{c}}$. On the other hand, high $Q_{\mathrm{m}}$ values more than 10,000 were obtained in the intermediate $T_{\mathrm{c}}$ compositions between at 500 to $750^{\circ} \mathrm{C}$. These values are quite high as the piezoelectric ceramics. The key point of the high $Q_{\mathrm{m}}$ in these compositions is the poling process at high temperature of $300^{\circ} \mathrm{C}$. These $Q_{\mathrm{m}}$ values are excellent for the ceramic resonator application with higher resonance stability as lead-free piezoelectric materials.

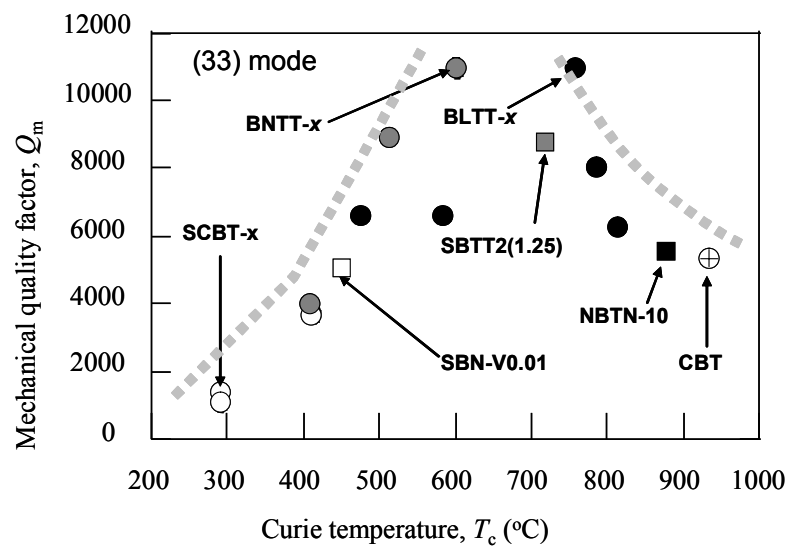

Fig. 1. Mechanical quality factor, $Q \mathrm{~m}$ versus Curie temperature, $T_{\mathrm{c}}$ of various bismuth layer-structured ferroelectrics 


\begin{abstract}
高い機械的品質係数を持つビスマス層状構造強誘電体セラミックス

$\begin{array}{rrrrrr}\text { 正 員 } & \text { 永田 } & \text { 肇* } & \text { 非会員 } & \text { 書間 } & \text { 裕二* } \\ \text { 非会員 } & \text { 鈴木 } & \text { 宗泰* } & \text { 正 員 } & \text { 竹中 } & \text { 正* }\end{array}$

\author{
Bismuth Layer Structured Ferroelectric Ceramics with High Mechanical Quality Factor \\ Hajime Nagata*, Member, Yuji Hiruma*, Non-member, Muneyasu Suzuki*, Non-member, Tadashi Takenaka*, Member
}

The piezoelectric properties in some bismuth layer-structured ferroelectric (BLSF) ceramics were investigated focusing on a mechanical quality factor, $Q_{\mathrm{m}}$. Many BLSF compositions with various Curie temperature, $T_{\mathrm{c}}$, were selected in this study, and the $Q_{\mathrm{m}}$ values of (33) mode were plotted as a function of their Curie temperature, $T_{\mathrm{c}}$. The $Q_{\mathrm{m}}$ increased with increasing the $T_{\mathrm{c}}$ in the low $T_{\mathrm{c}}$ compositions below $500^{\circ} \mathrm{C}$. It is considered to relate with the domain wall pinning because the coercive field, $E_{\mathrm{c}}$ also increased with increasing the $T_{\mathrm{c}}$. However, in the high $T_{\mathrm{c}}$ compositions above $750^{\circ} \mathrm{C}$, the $Q_{\mathrm{m}}$ decreased with increasing the $T_{\mathrm{c}}$ contrary, because of the difficulties in poling treatment due to the $E_{\mathrm{c}}$. On the other hand, high $Q_{\mathrm{m}}$ values more than 10,000 were obtained in the intermediate $T_{\mathrm{c}}$ compositions between at 500 to $750^{\circ} \mathrm{C}$. These values are quite high as the piezoelectric ceramics. The key point of the high $Q_{\mathrm{m}}$ in these compositions is the poling process at high temperature of $300^{\circ} \mathrm{C}$.
\end{abstract}

論 文

キーワード : ビスマス層状構造強誘電体, 機械品質係数, キュリー温度, セラミックレゾネータ, ドメインウォールモーション

Keywords : bismuth layer-structured ferroelectrics, mechanical quality factor; Curie temperature, ceramic resonator, domain wall motion

\section{1. はじめに}

現在実用化されている大部分の圧電セラミックスは，鉛 系の材料で，主成分として有害性が指摘されている酸化鉛 （PbO）を多量に含んでいる。近年，酸化鉛を含む圧電製品 の廃棄処理問題に関して, 無鉛圧電材料の開発が関心を集 めており, 環境にやさしい非鉛系圧電材料の研究開発は必 要不可欠であると考えられる。非鉛系圧電材料の候補とし

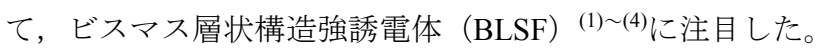

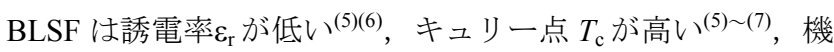
械的品質係数 $Q_{\mathrm{m}}$ が大きい $^{(8) \sim(14)}$, 共振周波数の温度変化率 $T C-f r$ が小さい(15) (18)などの特徴がある。このような特徵か ら BLSF はフィルタ,レゾネータなどに応用できると考えら れる。レゾネータとして応用する場合, 水晶の $Q_{\mathrm{m}}$ は $10^{6}$ 以 上と高いのに対し, 圧電セラミックスの $Q_{\mathrm{m}}$ は $10^{3}$ 程度と低 いが, 従来使われていた LC 型発振器の共振回路の $Q$ が $10^{2}$ と低いのに比べると 1 桁程度大きく, 発振安定性が向上す る。またセラミックスの一部をコンデンサとすることによ り C を含めたモノリシックなレゾネータを作製することが できる。市場では高精度の水晶発振器だけでなく, テレビ のリモコンなどに使用されている簡単な発振器を要求して

\footnotetext{
東京理科大学

干278-8510 千葉県野田市山崎 2641

Tokyo University of Science

2641 Yamazaki, Noda, Chiba-ken 278-8510
}

いる。しかし現在使用されている圧電セラミックスは鉛を 含む材料がほとんどである。このような理由から非鉛系圧 電材料の開発が必要である。BLSF を非鉛系圧電フィルタや レゾネータへ応用するためには, 更なる高機能化, すなわ ち, 高機械的品質係数化 $Q_{\mathrm{m}}$, 高電気的品質係数化 $Q_{\mathrm{emax}}$, 共 振周波数温度係数 $T C-f r$ の改善が必要である。本研究では, このうち, レゾネータの発振安定性に大きく寄与する $Q_{\mathrm{m}}$ に 着目し, BLSF セラミックスで大きな $Q_{\mathrm{m}}$ を得るための材料 設計の指針について検討した。

これまでに, BLSF セラミックスを用いた高 $Q_{\mathrm{m}}$ 化の研究 は企業を中心に行われてきた。例えば, $\mathrm{Bi}_{3} \mathrm{TiNbO}_{9}$ 系 ${ }^{(8)(9)}$ $\mathrm{CaBi}_{2} \mathrm{Ta}_{2} \mathrm{O}_{9}$ 系(10), $\mathrm{SrBi}_{2} \mathrm{Nb}_{2} \mathrm{O}_{9}$ 系 ${ }^{(14)(15)}$ の $\mathrm{BLSF}$ セラミックス において比較的大きな值（ 9000）が報告されている。しか し, これらの研究は様々な異なった振動モードについて検 討されていたり，測定方法が異なっていたりしたため，そ の BLSF 組成のもつ材料定数 $Q_{\mathrm{m}}$ として一概に比較すること ができなかった。今回我々は, 様々な BLSF セラミックスに おいて, (33)モードの基本波に限定して $Q_{\mathrm{m}}$ 值を評価するこ とにより，その BLSF 組成が持つ $Q_{\mathrm{m}}$ を系統的に比較した。 今回検討した様々な BLSF セラミックスを表 1 にまとめた。 特に, 幅広いキュリ一点 $T_{\mathrm{c}}$ をもつ組成群を選択し, $T_{\mathrm{c}}$ と $Q_{\mathrm{m}}$ との相関に着目して比較検討を行った。 
Table 1. The list of bismuth layer-structured ferroelectrics and their abbreviations and Curie temperatures, $T_{\mathrm{c}}$. The chemical formula of BLSF is generally represented by $\left(\mathrm{Bi}_{2} \mathrm{O}_{2}\right)^{2+}\left(\mathrm{A}_{m-1} \mathrm{~B}_{m} \mathrm{O}_{3 m+1}\right)^{2-}$, where $m$ is an integer corresponding to the number of $\mathrm{BO}_{6}$ octahedra in pseudo perovskite blocks.

\begin{tabular}{|c|c|c|c|}
\hline Composition & $\# m$ & abbreviation & $T_{\mathrm{c}}\left({ }^{\circ} \mathbf{C}\right)$ \\
\hline $\mathrm{CaBi}_{2} \mathrm{Ta}_{2} \mathrm{O}_{9}$ & 2 & CBT & 933 \\
\hline $0.9 \mathrm{Bi}_{3} \mathrm{TiNbO}_{9}-0.1 \mathrm{Na}_{0.5} \mathrm{Bi}_{2.5} \mathrm{Nb}_{2} \mathrm{O}_{9}$ & 2 & NBTN-10 & 895 \\
\hline $\mathrm{Bi}_{3-x} \mathrm{Nd}_{x} \mathrm{TiTaO}_{9}(0 \leqq x \leqq 1)$ & 2 & BNTT- $x$ & $400-900$ \\
\hline $\mathrm{Sr}_{x-1} \mathrm{Bi}_{4-x} \mathrm{Ti}_{2-x} \mathrm{Ta}_{\mathrm{x}} \mathrm{O}_{9}(1 \leq x \leq 2)$ & 2 & $\operatorname{SBTT2}(x)$ & $280-850$ \\
\hline $\mathrm{Bi}_{3-x} \mathrm{La}_{x} \mathrm{TiTaO}_{9}(0 \leqq x \leqq 1)$ & 2 & BLTT- $x$ & $200-900$ \\
\hline $\mathrm{SrBi}_{2} \mathrm{Nb}_{1.9} \mathrm{~V}_{0.1} \mathrm{O}_{9}$ & 2 & SBNV & 439 \\
\hline$\left(\mathrm{Sr}_{1-\mathrm{x}} \mathrm{Ca}_{\mathrm{x}}\right)_{2} \mathrm{Bi}_{4} \mathrm{Ti}_{5} \mathrm{O}_{18}(0 \leqq x \leqq 0.5)$ & 5 & SCBT $-x$ & $290-470$ \\
\hline
\end{tabular}

\section{2. 実験方法}

試料は通常の固相反応法により作製した。出発原料は各 イオンの酸化物, 水酸化物, 炭酸化物の純度 $99.9 \%$ 以上の原 料を使用した。これらの原料をボールミルにより混合し， 600-850 ${ }^{\circ} \mathrm{C}$ 1-2 時間で仮焼成をした。その後, 粉砕し冷間等 方加圧法 (CIP) を用いて $150 \mathrm{MPa}$ の圧力を 5 分間加えた後, 950- $1280^{\circ} \mathrm{C}$ で 2 時間の本焼成を行った。

得られた試料は, X 線回折によりビスマス層状構造単一 相であることを確認し格子定数を決定した。電気測定には 相対密度が $95 \%$ 以上の試料を使用し, 抵抗率, 誘電温度特 性, 圧電特性などの電気的諸特性の評価を通常の測定方法 で行った。強誘電体セラミックスに压電性を付与寸るため の分極処理は, シリコーンオイル中で, 印加電界 $E_{\mathrm{p}}=$ 7-20 kV/mm, 温度 $T_{\mathrm{p}}=100-300^{\circ} \mathrm{C}$ おび時間 $t_{\mathrm{p}}=2 \sim 15 \min$ の 条件で行った。圧電特性は EMAS 標準規格に基づき,イン ピーダンスアナライザー（HP4294A）を用いて，共振一反 共振法で測定した。機械的品質係数 $Q_{\mathrm{m}}$ は, 動アドミタンス 円から直列共振周波数 $f_{\mathrm{s}}$ を求め, 半値幅 $\Delta f$ との比から算出 した。電気的品質係数 $Q_{\text {emax }}$ は, 共振周波数 $f_{\mathrm{r}}$ と反共振周波 数 $f_{\mathrm{a}}$ の間, 寸なわちインダクタンス領域における最大位相 角 $\theta_{\max }$ の正接（tangent）をとることにより求めた。

\section{3. 実験結果および考察}

図 1 は, 各種 BLSF 組成における機械的品質係数 $Q_{\mathrm{m}}(33$ モード）とそのキュリー点 $T_{\mathrm{c}}$ の関係を示している。 $T_{\mathrm{c}}$ が $600^{\circ} \mathrm{C}$ 付近の BNTT- 0.5 において, $Q_{\mathrm{m}}$ は 11000 を示し, 強誘 電体セラミックスとしては極めて大きな值を持つことが分 かった。また, $T_{\mathrm{c}}$ が $500^{\circ} \mathrm{C}$ 程度までは, $T_{\mathrm{c}}$ の増加とともに, $Q_{\mathrm{m}}$ は増加し, $T_{\mathrm{c}}$ が $750^{\circ} \mathrm{C}$ 程度以上では, 逆に $T_{\mathrm{c}}$ の増加とと もに， $Q_{\mathrm{m}}$ は減少する傾向があることが分かった。これより， BLSF セラミックスにおける $Q_{\mathrm{m}}$ 值は，それらの $T_{\mathrm{c}}$ と何らか の相関があることが示唆された。 $T_{\mathrm{c}}$ と $Q_{\mathrm{m}}$ の相関を元に, $T_{\mathrm{c}}$ $<500^{\circ} \mathrm{C}$ の組成を Low $T_{\mathrm{c}}$ 組成, $500{ }^{\circ} \mathrm{C}<T_{\mathrm{c}}<750^{\circ} \mathrm{C}$ の組成を Intermediate $T_{\mathrm{c}}$ 組成, $T_{\mathrm{c}}>750^{\circ} \mathrm{C}$ 組成を High $T_{\mathrm{c}}$ 組成と分類 し, 各領域における代表的な共振反共振波形を図 2 に示し

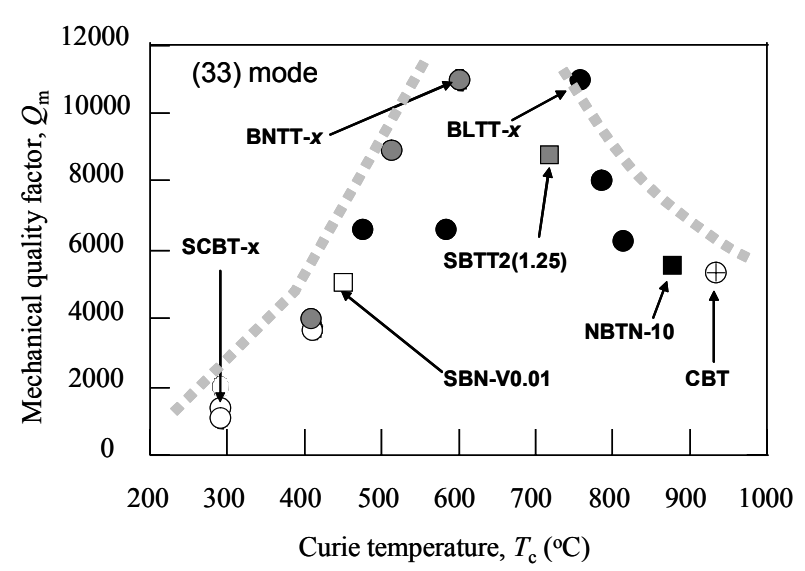

Fig. 1. Mechanical quality factor, $Q_{\mathrm{m}}$ versus Curie temperature, $T_{\mathrm{c}}$ of various bismuth layer-structured ferroelectrics.

Table 2. Poling conditions of (a) $\mathrm{SrBi}_{2} \mathrm{Nb}_{1.9} \mathrm{~V}_{0.1} \mathrm{O}_{9}$, (b) $\mathrm{Sr}_{0.25}$ $\mathrm{Bi}_{3.75} \mathrm{Ti}_{0.75} \mathrm{Ta}_{1.25} \mathrm{O}_{9}$ and (c) $\mathrm{CaBi}_{2} \mathrm{Ta}_{2} \mathrm{O}_{9}$ ceramics.

\begin{tabular}{|c|c|c|c|c|c|}
\hline Composition & Abbreviation & $\begin{array}{c}T_{\mathrm{c}} \\
\left({ }^{\circ} \mathbf{C}\right)\end{array}$ & $\begin{array}{c}\text { Poling } \\
\text { Field, } E_{\mathrm{p}} \\
(\mathrm{kV} / \mathrm{mm})\end{array}$ & $\begin{array}{l}\text { Poling } \\
\text { Temp., } \\
T_{\mathrm{p}}\left({ }^{\circ} \mathrm{C}\right)\end{array}$ & $\begin{array}{c}\text { Poling } \\
\text { Time, } \\
t_{\mathrm{p}}(\mathrm{min})\end{array}$ \\
\hline (a) $\mathrm{SrBi}_{2} \mathrm{Nb}_{1.9} \mathrm{~V}_{0.1} \mathrm{O}_{9}$ & SBN & 439 & 8 & 150 & 5 \\
\hline (b) $\mathrm{Sr}_{0.25} \mathrm{Bi}_{3.75} \mathrm{Ti}_{0,75} \mathrm{Ta}_{1.25} \mathrm{O}_{9}$ & SBTT2(1.25) & 705 & 8 & 300 & 7 \\
\hline (c) $\mathrm{CaBi}_{2} \mathrm{Ta}_{2} \mathrm{O}_{9}$ & CBT & 933 & 12 & 200 & 10 \\
\hline
\end{tabular}

た。図 2(a)は, $T_{\mathrm{c}}=439^{\circ} \mathrm{C} の \mathrm{SBN}-\mathrm{V} 0.01$, (b)は, $T_{\mathrm{c}}=705^{\circ} \mathrm{C}$ の $\operatorname{SBTT2}(1.25),(\mathrm{c})$ は, $T_{\mathrm{c}}=933^{\circ} \mathrm{C}$ の CBT セラミックスの共振反 共振波形である。(a)SBN および(c)CBT の $Q_{\mathrm{m}}$ 值は，5500 と 同程度であるが，その共振反共振波形は大きく異なってい る。(a)SBN の共振反共振波形では, インダクタンス領域の 位相の最大值 $\theta_{\max }$ が $88^{\circ}$ 以上, また $Q_{\mathrm{e}}$ 值で表すと $20(=\tan$ $\left.\theta_{\max }\right)$ 以上であり, 十分に位相が反転した良好な共振反共振 波形を示していることがわかる。一方で, (c)CBT の共振反 共振波形では, インダクタンス領域の位相の最大值 $\theta_{\max }$ は $80^{\circ}$ 程度と低く, 位相の反転は十分とはいえない。このよう に, 同程度の $Q_{\mathrm{m}}$ を持つ組成でも, Low $T_{\mathrm{c}}$ 組成では十分に位 相が反転し, High $T_{\mathrm{c}}$ 組成では, 位相の反転は十分ではなか った。また, Intermediate $T_{\mathrm{c}}$ 組成の(b)SBTT では, 比較的良 く位相が反転しており, かっ大きな $Q_{\mathrm{m}}$ 值を持っていること が分かる。強誘電体セラミックスでは, 圧電性を付与する ための分極処理が必要であり, 一般に, 分極反転が進むに つれて, インダクタンス領域の位相の最大值は, より $90^{\circ}$ に近づく。すなわち, 分極処理による分極反転の度合いが, 共振反共振波形に強く影響を及ぼしており, Low $T_{\mathrm{c}}$ 組成で は十分に分極反転が進み, High $T_{\mathrm{c}}$ 組成では分極反転が不十 分であったと考えられる。表 2 に(a) SBN-V0.01, (b) SBTT2 (1.25), (c) CBT セラミックスの分極処理条件（電界 $E_{\mathrm{p}}$, 温 度 $T_{\mathrm{p}}$, 時間 $t_{\mathrm{p}}$ ) を示寸。CBT セラミックスでは, SBN-V0.01 に較べて, より高電界, 高温, 長時間の分極処理を施した。 しかしながら，上述のとおり，分極反転は不十分であるこ 
(a)SBN-V0.01 $\left(T_{\mathrm{c}}=439^{\circ} \mathrm{C}\right)$

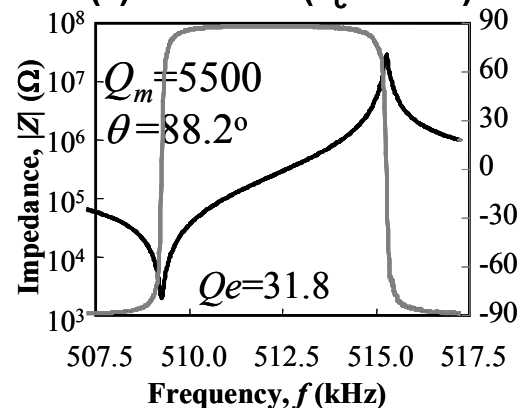

(b)SBTT2(1.25) $\left(T_{c}=705^{\circ} \mathrm{C}\right)$

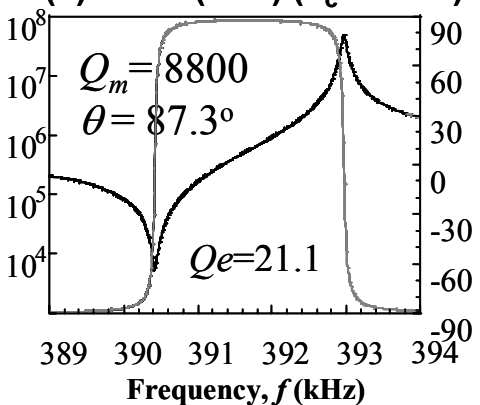

(c) CBT $\left(T_{\mathrm{c}}=933^{\circ} \mathrm{C}\right)$

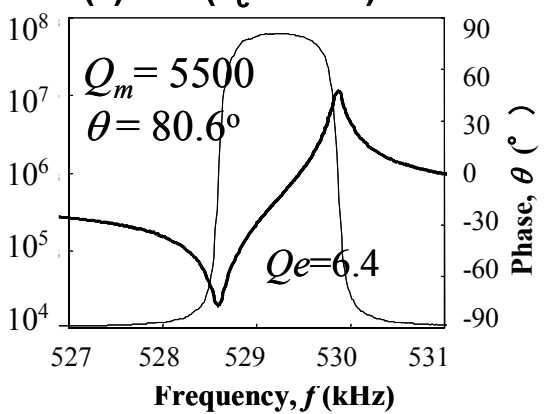

Fig. 2. Frequency dependence of impedance, $\mathrm{Z}$, of (33) mode for (a) $\mathrm{SrBi}_{2} \mathrm{Nb}_{1.9} \mathrm{~V}_{0.1} \mathrm{O}_{9}$, (b) $\mathrm{Sr}_{0.25} \mathrm{Bi}_{3.75} \mathrm{Ti}_{0.75} \mathrm{Ta}_{1.25} \mathrm{O}_{9}$ and (c) $\mathrm{CaBi}_{2} \mathrm{Ta}_{2} \mathrm{O}_{9}$ ceramics.

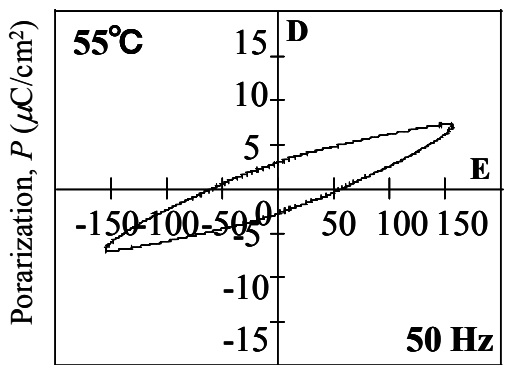

Applied field , $E_{\mathrm{a}}(\mathrm{kV} / \mathrm{cm})$

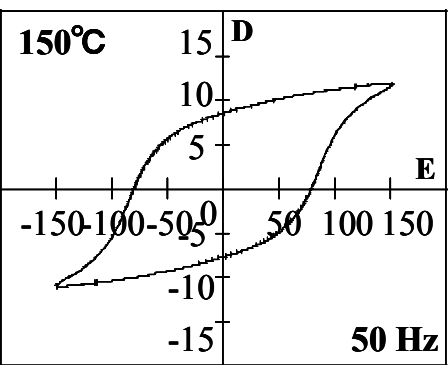

Applied field, $E_{\mathrm{a}}(\mathrm{kV} / \mathrm{cm})$

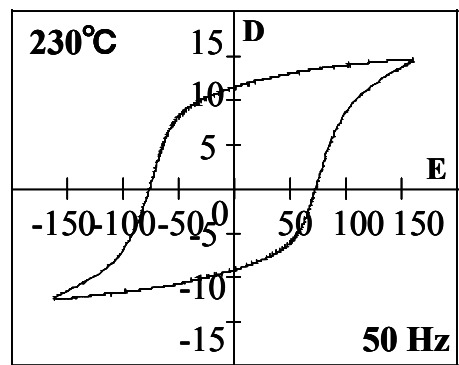

Applied field , $E_{\mathrm{a}}(\mathrm{kV} / \mathrm{cm})$

Fig. 3. D-E hysteresis loops of $\mathrm{Sr}_{0.25} \mathrm{Bi}_{3.75} \mathrm{Ti}_{0.75} \mathrm{Ta}_{1.25} \mathrm{O}_{9}$, SBTT2 (1.25), ceramic measured at 55,150 and $230^{\circ} \mathrm{C}$.

とから, High $T_{\mathrm{c}}$ 組成では分極反転が非常に困難であると考 えられる。一方, Low $T_{\mathrm{c}}$ 組成 $(\mathrm{SBN})$ では, 弱い分極条件 にも係わらず, 十分に飽和した共振反共振波形がえられて いる。これより，図 1 の Low $T_{\mathrm{c}}$ 組成では，十分に分極反転 が飽和した際の $Q_{\mathrm{m}}$ (本来その材料が持っていると考えられ る $\left.Q_{\mathrm{m}}\right)$ を示しており, High $T_{\mathrm{c}}$ 組成では，分極反転の度合い に強く依存した $Q_{\mathrm{m}}$ を示していると考えられる。すなわち, BLSF セラミックスでは本来, $T_{\mathrm{c}}$ の上昇に伴って $Q_{\mathrm{m}}$ は上昇 する傾向にあるが, High $T_{\mathrm{c}}$ 組成では，分極処理が困難であ るために, 本来の高い $Q_{\mathrm{m}}$ が引き出せていないと考えられる。

上述の考察より, Intermediate $T_{\mathrm{c}}$ 組成の領域は， $T_{\mathrm{c}}$ の上昇 に伴う高 $Q_{\mathrm{m}}$ 化と，分極反転が困難さに伴う低 $Q_{\mathrm{m}}$ 化の両者 のバランスが取れた領域であると考えられる。従って，こ の組成領域での $Q_{\mathrm{m}}$ 值は, 分極処理条件に非常に敏感である と推察される。図 3 は, SBTT2 セラミックスの(a) $55^{\circ} \mathrm{C}$, (b) $150^{\circ} \mathrm{C}$, (c) $230^{\circ} \mathrm{C}$ における D-E ヒステリシスループである。 これより, 測定温度を上げるに従って, より飽和したヒス テリシスループが得られている。すなわち, 測定温度の上 昇に伴って，分極反転が容易になっていることが分かる。 そこで, 分極処理温度 $T_{\mathrm{p}}$ を変化させた際の, $Q_{\mathrm{m}}$ の分極電界 印加特性を調べた。図 4 は, SBTT2 セラミックスの(p)モー ド (Radial Mode) における $Q_{\mathrm{m}}$ の分極印加電界特性である $\left(T_{\mathrm{p}}=240^{\circ} \mathrm{C}, 300^{\circ} \mathrm{C}\right) 。 T_{\mathrm{p}}$ が $240^{\circ} \mathrm{C}$ のき， $Q_{\mathrm{m}}$ は $6000-8000$ 程 度であったが， $T_{\mathrm{p}}$ が $300^{\circ} \mathrm{C}$ のき， 10000 を超える大きな $Q_{\mathrm{m}}$ を示すことがわかった。すなわち, SBTT2 セラミックス

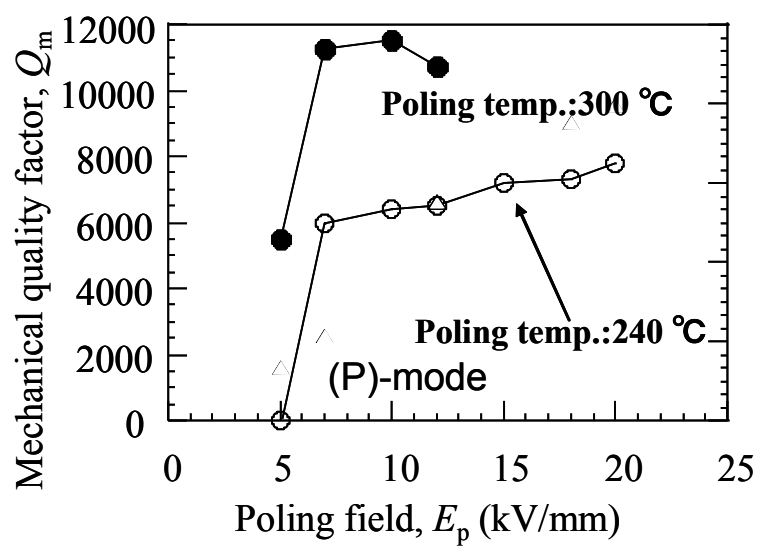

Fig. 4. Mechanical quality factor, $Q_{\mathrm{m}}$, as a function of the poling field, $E_{\mathrm{p}}$ at the poling temperature of 240 and $300^{\circ} \mathrm{C}$ for $\mathrm{Sr}_{0.25} \mathrm{Bi}_{3.75} \mathrm{Ti}_{0.75} \mathrm{Ta}_{1.25} \mathrm{O}_{9}$, SBTT2(1.25), ceramic.

において, 高温での分極処理が高 $Q_{\mathrm{m}}$ 化にとって有効な手段

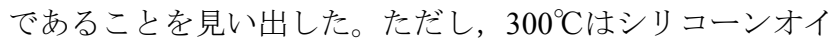
ルの使用限界温度であり， $300^{\circ} \mathrm{C} よ り$ 高温での分極処理を行 うことはできなかった。これらの結果は, 高温での分極処 理によって分極反転を進ませたことにより SBTT2 セラミッ クスが本来持つ大きな $Q_{\mathrm{m}}$ を引き出すことができたものと考 えられる。

図 5 は, CBT セラミックスの $Q_{\mathrm{m}}$ と位相の最大值 $\theta_{\max }$ との 関係である。 $\theta_{\max }$ は, 分極条件を変化させることによりコン 


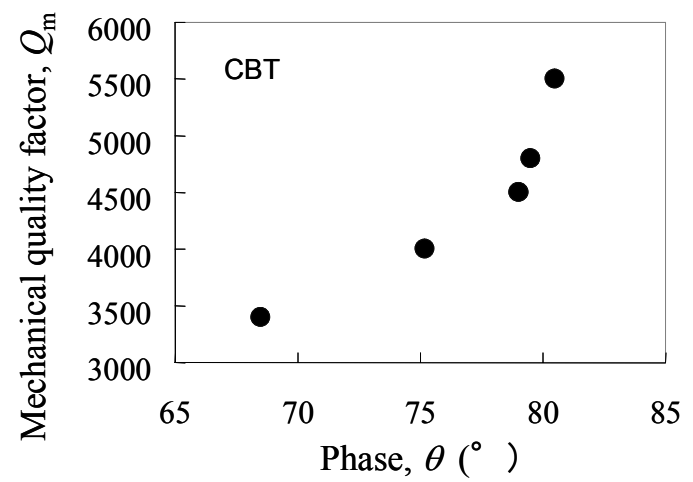

Fig. 5. Mechanical quality factor, $Q_{\mathrm{m}}$, as a function of the maximum phase, $q$, in the inductance region between resonance and anti-resonance frequency on $\mathrm{CaBi}_{2} \mathrm{Ta}_{2} \mathrm{O}_{9}$ ceramic.

トロールした。表 2 に示した分極条件のとき， $\theta_{\max }$ は最も大 きく, $80.6^{\circ}$ であった。 $200^{\circ} \mathrm{C}$ 以上の高温での分極処理は, リ 一ク電流の増大にため行うことができなかった。図 5 より, $\theta_{\max }$ が上昇するに従って， $Q_{\mathrm{m}}$ 值は増加していることがわか る。すなわち, 分極反転の度合いが進むに従って, $Q_{\mathrm{m}}$ 值は 指数関数的に上昇した。フィッティングカーブから， $\theta_{\max }$ が $90^{\circ}$ に近づいたときの $Q_{\mathrm{m}}$ 值を算出したところ， 25000 程 度となり, $\mathrm{CBT}$ セラミックスを十分に分極反転させること ができた場合, 非常に大きな $Q_{\mathrm{m}}$ 值が期待されることがわか る。

これまでの結果より, 高い $T_{\mathrm{c}}$ をもつ BLSF セラミックス は，大きな $Q_{\mathrm{m}}$ を有することが明らかになってきた。ここで は, 高い $T_{\mathrm{c}}$ 組成で大きな $Q_{\mathrm{m}}$ が得られた背景について検討す る。BLSF の $T_{\mathrm{c}}$ は，一般に D-E ヒステリシスループの抗電 界 $E_{\mathrm{c}}$ と相関があることが知られており, $T_{\mathrm{c}}$ の増加に伴って, $E_{\mathrm{c}}$ は増加する ${ }^{(19)(20)} 。 T_{\mathrm{c}}$ は, 室温付近での格子ひずみや自発 分極 $P_{\mathrm{s}}$ を 0 にする温度（熱エネルギー）を意味しており， $E_{\mathrm{c}}$ は電界の印加により $P_{\mathrm{s}}$ を 0 にする電界（電気的エネルギ 一）を意味している。従って， $P_{\mathrm{s}}$ を 0 にするという観点で, 両者は Intrinsic に一致する。また, セラミックスにおいて $E_{\mathrm{c}}$ は, グレイン内のドメインウォールを動かすのに必要な 電界である。一方で，ドメインウォールモーションは，弾 性的な損失を伴うと考えられるので, 弾性損失の逆数と定 義される $Q_{\mathrm{m}}$ に強く影響を及ぼす。例えば, $\mathrm{Pb}(\mathrm{Zr}, \mathrm{Ti}) \mathrm{O}_{3}(\mathrm{PZT})$ 系セラミックスでは，大きな $E_{\mathrm{c}}$ を持つハード系 $\mathrm{PZT}$ におい て, 大きな $Q_{\mathrm{m}}$ が得られている(21)(22)。ハード系 PZT では, 導入された酸素欠陥がドメインウォール付近に数多く存在 し，ドメインウォールモーションをピニングしているため,

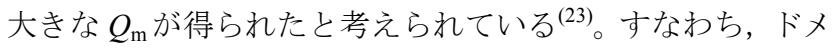
インウォールモーションを極力抑えることは, 高 $Q_{\mathrm{m}}$ 化に有 効である。本実験における一連の BLSF セラミックスでは, $T_{\mathrm{c}}$ の増加すなわち $E_{\mathrm{c}}$ の増加に伴って, ドメインウォールモ ーションが抑制されることにより， $Q_{\mathrm{m}}$ が増加したと考えら れる。また, Intermediate $T_{\mathrm{c}}$ 組成では, 分極処理で高い温度

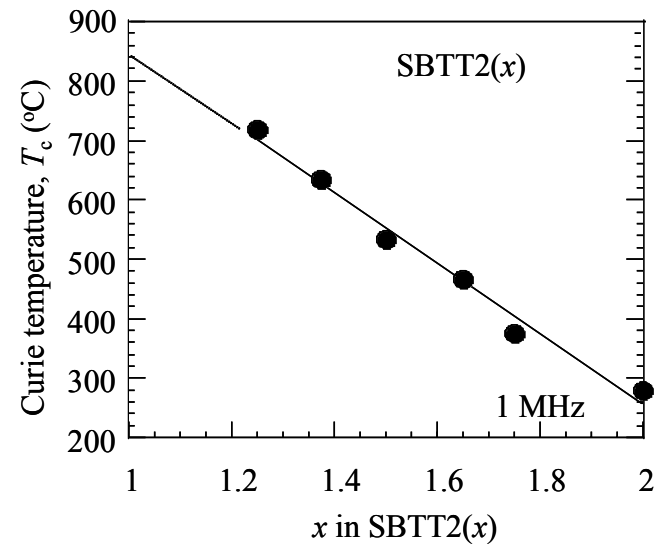

Fig. 6. Compositional dependence of Curie temperature, $T_{\mathrm{c}}$ for SBTT2 $(x)$ ceramics.

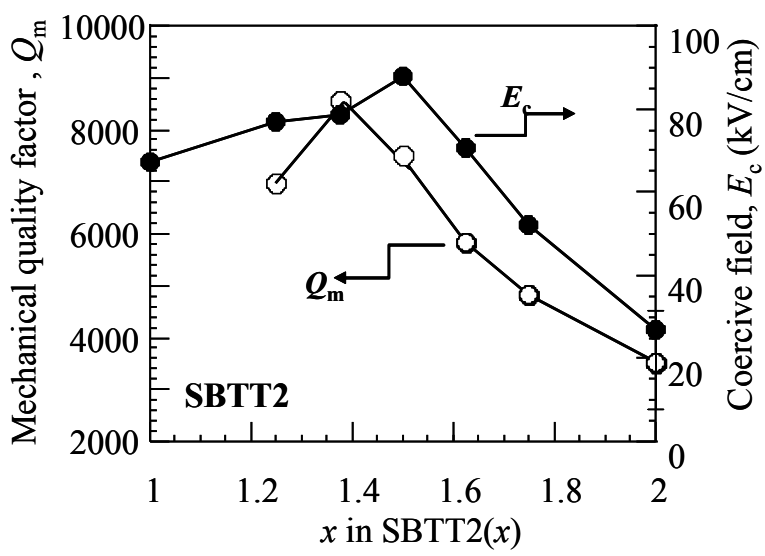

Fig. 7. Compositional dependence of mechanical quality factor, $Q_{\mathrm{m}}$, and coercive field, $E_{\mathrm{c}}$, for SBTT2 $(x)$ ceramics.

および電界を印加してドメインウォールを強制的に動かし た後, その状態で, 高 $E_{\mathrm{c}}$ によってドメインウォールがピニ ングされるため, 高 $Q_{\mathrm{m}}$ が得られたと考えられる。

図 6 および図 7 は, $\mathrm{Sr}_{x-1} \mathrm{Bi}_{4-x} \mathrm{Ti}_{2-x} \mathrm{Ta}_{x} \mathrm{O}_{9}$ 系セラミックスの $T_{\mathrm{c}}, E_{\mathrm{c}}, Q_{\mathrm{m}}$ の組成依存性である。図 6 より, $x$ が減少するに 従って, $T_{\mathrm{c}}$ は増加した。 $T_{\mathrm{c}}$ の増加傾向と同様に, $x$ の減少と ともに $E_{\mathrm{c}}$ も増加するが, $x=1.5$ 付近で最大值をとった後, 減 少した。 $E_{\mathrm{c}}$ が減少した領域では, 飽和した $D-E$ ヒステリシ スループが得られなかったことから, 分極反転が困難であ るために本来その組成が持っている $E_{\mathrm{c}}$ を引き出せなかった ものと考えられる。また, $Q_{\mathrm{m}}$ は $E_{\mathrm{c}}$ の挙動と同様に振舞って おり， $Q_{\mathrm{m}}$ と $E_{\mathrm{c}}$ は密接に関係してことがわかる。このような 傾向は, 他の BLSF の組成系においても, 過去に報告されて いる(8)(10)。これらの結果より, BLSF セラミックスでは, 高 $T_{\mathrm{c}}$ 組成ほど高 $E_{\mathrm{c}}$ を持つことから, 高 $Q_{\mathrm{m}}$ 化が期待されるが, 分極反転が困難なほど $E_{\mathrm{c}}$ が大きくなると, 本来の $Q_{\mathrm{m}}$ を引 き出すことは困難になる。高 $T_{\mathrm{c}}$ 組成で本来の $Q_{\mathrm{m}}$ を引き出す ためには, 厳しい分極条件での分極処理が必要であり, 本 
研究では，高温での分極処理が有効であることを示した。 しかし，このような高温での分極処理ではリーク電流が増 大し，良好な分極反転をさせることが困難となる。そのた め, 高温で高い抵抗率を持っていることが求められる。以 上のことから，BLSF セラミックスにおいて大きな $Q_{\mathrm{m}}$ を持 つ材料の開発を行うためには， $T_{\mathrm{c}}$ もしくは $E_{\mathrm{c}}$ が大きく，か つ抵抗率の高い材料が望まれる。

\section{4. まとめ}

様々なビスマス層状構造強誘電体セラミックスの機械的 品質係数 $Q_{\mathrm{m}}$ を, キュリー点 $T_{\mathrm{c}}$ に着目して系統的に評価・比 較を行った。その結果，以下の点が明らかになった。

(1) $T_{\mathrm{c}}$ が, $T_{\mathrm{c}}<500^{\circ} \mathrm{C}$ 程度の組成では， $T_{\mathrm{c}}$ の増加ととも に $Q_{\mathrm{m}}$ は増加した。

（2） $T_{\mathrm{c}}$ が， $500<T_{\mathrm{c}}<750^{\circ} \mathrm{C}$ 程度の組成では，10000を超 える $Q_{\mathrm{m}}$ を示すことがわかった。このとき, 高温 $\left(300^{\circ} \mathrm{C}\right)$ での 分極処理が有効であることがわかった。

(3) $T_{\mathrm{c}}$ が， $T_{\mathrm{c}}>750^{\circ} \mathrm{C}$ 程度の組成では，分極処理時に分 極反転し難いことから，本来持っていると考えられる大き な $Q_{\mathrm{m}}$ を引き出すことが困難であった。

(4)これら $T_{\mathrm{c}}$ と $Q_{\mathrm{m}}$ の相関は, 抗電界 $E_{\mathrm{c}}$ を介して, ドメ インウォールモーションと密接な関係があることがわかっ た。

\section{謝 辞}

本研究の一部は，日本学術振興会・科学研究費補助金·基 盤研究(B) (No. 17360327) の援助の元に行われた。また, 原 料に用いた高純度の酸化チタン粉末は, TOHO TITANIUM CO. LTD より提供頂いた。上記の各位に心より感謝致しま す。

(平成 18 年 11 月 28 日受付，平成 19 年 2 月 21 日再受付)

\section{文献}

(1) B. Aurivillius : "Mixed Bismuth Oxides with Layer Lattices", Ark. Kemi., Vol.1, p.499 (1949)

(2) G. A. Smolenskii, V. A. Isupov, and A. I. Agranovskaya : "Ferroelectrics of the Oxygen-Octahedral Type with Layered Structure", Sov. Phys.-Solid State, Vol.3, No.3, p.651 (1961)

( 3 ) E. C. Subbarao : "Crystal Chemistry of Mixed Bismuth Oxide with Layer-Type Structure", J. Am. Ceram. Soc., Vol.45, No.4, p.166 (1962)

(4) L. E. Cross and R. C Pohanka : "Ferroelectricty in Bismuth Oxides Type Layer Structure Compounds", Mat. Res. Bull., Vol.6, p.939 (1971)

(5) S. Ikegami and I. Ueda : "Piezoelectricity in Ceramic of Ferroelectric Bismuth Compound with Layer Structure", Jpn. J. Appl. Phys., Vol.13, No.10, pp.1572-1577 (1974-10)

(6) T. Takenaka and K. Sakata : "Dielectric and Piezoelectric Properties of Some Bismuth Layer-Structure Ferroelectric Ceramics", Jpn. J. IEEE (C), Vol.J65-C, p.512 (1982) (in Japanese)

(7) H. Nagata, T. Takahashi, and T. Takenaka : "Piezoelectric Anisotropies of Bismuth Layer-Structured Ferroelectrics", Transactions of the Materials Research Society of Japan, Vol.25, No.1, p.273 (2000)

( 8 ) M. Nanao, M. Hirose, and T. Tsukada : "Piezoelectric properties of $\mathrm{Bi}_{3} \mathrm{TiNbO}_{9}-\mathrm{BaBi}_{2} \mathrm{Nb}_{2} \mathrm{O}_{9}$ ceramics”, Jpn. J. Appl. Phys., Vol.40, 9B, pp.5727-5730 (2001-9)

(9) Y. Sugaya, K. Shoji, and K. Sakata : "Fabrication and Characterization of LnBi ${ }_{2} \mathrm{TiNbO}_{9}$-Based Ceramics", Jpn. J. Appl. Phys., Vol.42, pp.6086-6089
(2003)

(10) K. Shibata, K. Shoji, and K. Sakata : " $\mathrm{Sr}_{1-x} \mathrm{Ca}_{x} \mathrm{Bi}_{2} \mathrm{Ta}_{2} \mathrm{O}_{9}$ Piezoelectric Ceramics with High Mechanical Quality Factor", Jpn. J. Appl. Phys., Vol.40, 9B, pp.5719-5721 (2001-9)

(11) H. Oka, M. Hirose, T. Tsukada, Y. Watanabe, and T. Nomura : "Thicknessshear vibration mode characteristics of $\mathrm{SrBi}_{4} \mathrm{Ti}_{4} \mathrm{O}_{15}$-based ceramics", Jpn. J. Appl. Phys., Vol.39, 9B, pp.5613-5615 (2000-9)

(12) H. Nagata, M. Itagaki, and T. Takenaka : "Properties of Bismuth LayerStructured Ferroelectric $\mathrm{SrBi}_{2} \mathrm{Ta}_{2} \mathrm{O}_{9}-\mathrm{Bi}_{3} \mathrm{TiTaO}_{9}$ Ceramics", Ferroelectrics, Vol.286, pp.85-92 (2003)

(13) M. Suzuki, H. Nagata, H. Funakubo, and T. Takenaka : "Piezoelectric properties of lanthanum modified $\mathrm{Bi}_{3} \mathrm{TiTaO}_{9}$ ceramics", Key Engineering Materials (Electroceramics VI in Japan), Vol.248, pp.11-14 (2003)

(14) M. Hirose, T. Suzuki, H. Oka, K. Itakura, Y. Miyauchi, and T. Tsukada : "Piezoelectric properties of $\mathrm{SrBi}_{4} \mathrm{Ti}_{4} \mathrm{O}_{15}$-based ceramics", Jpn. J. Appl. Phys., Vol.38, 9B, pp.5561-5563 (1999-9)

(15) T. Sawada, A. Ando, Y. Sakabe, D. Damjanovic, and N. Setter : "Properties of the elastic anomaly in $\mathrm{SrBi}_{2} \mathrm{Nb}_{2} \mathrm{O}_{9}$-based ceramics", Jpn. J. Appl. Phys., Vol.42, 9B, pp.6094-6098 (2003-9)

(16) A. Ando, M. Kimura, and Y. Sakabe : "Piezoelectric properties of Ba and $\mathrm{Ca}$ doped $\mathrm{SrBi}_{2} \mathrm{Nb}_{2} \mathrm{O}_{9}$ based ceramic materials", Jpn. J. Appl. Phys., Vol.42, 2A, pp.520-5525 (2000-2)

(17) H. Ogawa, M. Kimura, A. Ando, and Y. Sakabe : "Temperature dependence of piezoelectric properties of grain-oriented $\mathrm{CaBi}_{4} \mathrm{Ti}_{4} \mathrm{O}_{15}$ ceramics", Jpn. J. Appl. Phys., Vol.40, 9B, pp.5715-5718 (2001-9)

(18) A. Ando, T. Sawada, H. Ogawa, M. Kimura, and Y. Sakabe : "Finetolerance resonator applications of bismuth-layer-structured ferroelectric ceramics", Jpn. J. Appl. Phys., Vol.41, 11B, pp.7057-7061 (2002-11)

(19) H. Irie, M. Miyayama, and T. Kudo : "Structure dependence of ferroelectric properties of bismuth layer-structured ferroelectric single crystals", J. Appl. Phys., Vol.90, No.8, pp.4089 (2001)

(20) Y. Noguchi, H. Shimizu, M. Miyayama, K. Oikawa, and T. Kamiyama : "Ferroelectric Properties and Structure Distortion in $A$-Site-Modified $\mathrm{SrBi}_{2} \mathrm{Ta}_{2} \mathrm{O}_{9} "$, Jpn. J. Appl. Phys., Vol.40, pp.5812-5815 (2001)

(21) S. Takahashi, Y. Sasaki, S. Hirose, and K. Uchino : "Stability of $\mathrm{PbZrO}_{3}$ $\mathrm{PbTiO}_{3}-\mathrm{Pb}\left(\mathrm{Mn}_{1 / 3} \mathrm{Sb}_{2 / 3}\right) \mathrm{O}_{3}$ Piezoelectric Ceramics under Vibration-Level Change", Jpn. J. Appl. Phys., Vol.34, 9B, pp.5328-5331 (1995)

(22) T. Kamiya, T. Suzuki, T. Tsurumi, and M. Daimon : "Effects of Manganese Addition on Piezoelectric Properties of $\mathrm{Pb}\left(\mathrm{Zr}_{0.5} \mathrm{Ti}_{0.5}\right) \mathrm{O}_{3}$ ”, Jpn. J. Appl. Phys., Vol.31, 9B, pp.3058-3060 (1992)

(23) P. Gerthsen, K. H. Hardtl, and N. A. Schmidt : "Correlation of mechanical and electrical losses in ferroelectric ceramics", J. Appl. Phys. Vol.51, No.2, pp.1131-1134 (1980-2)

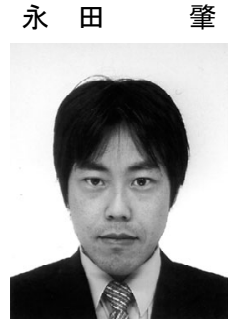

（正員） 1972 年 6 月生。2001 年 3 月, 東京理 科大学大学院理工学研究科博士後期課程修了。 同年 4 月, 同大学理工学部電気工学科（現電気 電子情報工学科) 嘱託助手。2003 年 9 月 2005 年 8 月, The Pennsylvania State University, Materials Research Institute（USA）ポストドクト ラル研究員。2005 年 9 月, 東京理科大学理工学 部電気電子情報工学科, 嘱託助手 (助教), 現 在に至る。主に, 環境調和型非鉛圧電セラミックスの開発に関する 研究に従事。2007 年第 61 回日本セラミックス協会進歩賞受賞。

間 裕 二

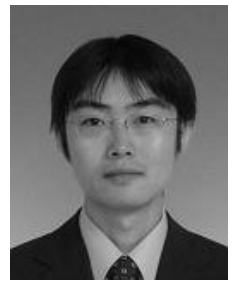

（非会員） 1977 年生。 2007 年 3 月，東京理科 大学大学院理工学研究科博士後期課程修了。同 年 4 月, 東京理科大学理工学部電気電子情報工 学科, 嘱託助手(助教)。現在に至る。非鉛強誘 電体セラミックスの作製と, その強誘電性, 圧 電性の評価に従事。博士（工学） 
鈴 木 宗 泰 (非会員) 1977 年 12 月 27 日生。 2006 年 4 月 東京工業大学大学院総合理工学研究科博士後 期課程を修了。同年 4 月, 東京理科大学大学院 理工学研究科 ポストドクトラル研究員。2007 年 2 月, 東京大学先端科学技術研究センター産 学官連携研究員。現在に至る。主に, ビスマス 層状構造酸化物を中心とした非鉛系強誘電体 酸化物の合成と物性解析に従事。博士 (工学)。
竹中 正 (正員) 1946 年 7 月 31 日生。1970年 3 月芝

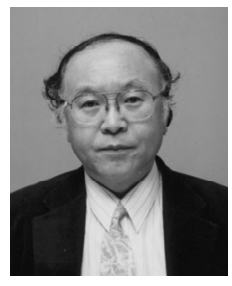
浦工業大学・工・電子工学科卒業。1973 年 3 月電気通信大学大学院 $\cdot$ 電気通信学研究科 $\cdot$ 通 信材料工学専攻修士課程修了。同年 4 月東京理 科大学・理工学部・電気工学科助手, その後, 講師・助教授を経て, 1996 年 4 月同学科教授。 現在, 同学部・電気電子情報工学科教授。工学 博士 $(1985$ 年京都大学)。1986 年 8 月から 1 年 間, 米国・ペンシルベニア州立大学・材料科学研究所客員研究員。 1993 年米国・セラミックス協会（電子部門）Edward C. Henry Award (論文賞) 受賞。2001 年 (社) 日本セラミックス協会・第 55 回学術 賞受賞。2005-06 年, IEEE Ultrasonics, Ferroelectrics, and Frequency Control Japan Chapter (UFFC-20) 委員長。2006年1月から IEEE UFFC Administrative Committee 委員。1974 年から現在まで, 非鉛系圧電セ ラミックスおよび粒子配向型強誘電体セラミックスに関する研究 に従事。 